\title{
The Impact of Gamified Instruction on Students' Learning Outcomes: Systematic Review of Experimental Studies
}

\author{
Nevena Jaftha ${ }^{1}$, Marouska Zahra-Micallef ${ }^{1} \&$ Tatjana Chircop ${ }^{1, *}$ \\ ${ }^{1}$ Malta College of Arts, Science and Technology (MCAST), Triq Kordin, Paola, PLA 9032, \\ Malta \\ *Corresponding author: Malta College of Arts, Science and Technology (MCAST), Triq \\ Kordin, Paola, PLA 9032, Malta. Tel: 56-2398-7132. E-mail: tatjana.chircop@mcast.edu.mt
}

Received: October 8, 2021 Accepted: November 3, 2021 Published: November 12, 2021

doi:10.5296/ije.v13i4.19193ＵRL: https://doi.org/10.5296/ije.v13i4.19193

\begin{abstract}
This systematic review critically explores the intervention design and findings of the experimental studies that were published between January 2012-December 2020 in a number of digital libraries and databases and had the effect of a gamified instruction on students' learning outcomes in their focus, with the aim of identifying what constitutes success or the lack thereof in the given context. The found effect(s) of gamified instruction on students' learning engagement and achievement are discussed in relation to the a) intervention design, its flaws and their potential impact on reported outcomes and b) prevalent practice in gamification research. The discussion is structured around data collection sources, sample size, and intervention duration, but also the characteristics of learning technology, learning approach, course content, type of games and game elements. This study proposes a list of categories to be included in the description of a study context so that it is possible to a) systematically organise research findings, b) filter the variety of findings via means of replication studies. c) recognise the variant effect on different sub-populations, and d) suggest the way forward when designing and implementing gamified instruction within specific conditions. Furthermore, the study highlights the necessity of approaching the topic through a mixed-method approach involving a more intensive tracking schedule with new assessment instruments and a larger number of participants that are longitudinal or at least of a longer duration in order to obtain more comprehensive findings.
\end{abstract}

Keywords: gamification, serious games, game-based learning, pedagogical issues, integrating technology in curriculum 


\section{Introduction}

Gamification is a relatively new phenomenon that builds on established game-design principles and an understanding of human nature (Chou, 2016). Werbach and Hunter (2012) define game design elements as pyramidal hierarchies composed of three layers: components, mechanics and dynamics. Being grounded in behavioural economics and psychology, gamification allows designers to achieve intervention objectives (Chou, 2016; Wood \& Reiners, 2015). Four main application fields are product gamification, workplace gamification, marketing gamification and lifestyle gamification (Chou, 2016). Correspondingly, the theoretical rationale behind a specific gamification design relies on field-specific theories and general psychology theories that explain human nature and behaviour in a given context.

Lifestyle gamification involves applying game-design principles into people's daily activities and habits, and one of the sectors where it branches is education (Chou, 2016). Unlike serious games (that are not designed for pure entertainment but for provoking a thought and/or delivering a message, developing skills, teaching a lesson, providing experience and emotions, or changing behaviour and attitudes (Nguyen, Ishmatova, Tapanainen, Liukkonen, Katajapuu, Makila, Luimula, 2017; Duin, Hauge, Hunecker, Thoben, 2011; Deterding, Khaled, Nacke \& Dixon, 2011), gamification is not designed to influence learning directly, but to alter learners' attitude or behaviour and improve already existing instruction as a consequence of this change in the attitude or behaviour (Landers, 2014; Koivisto \& Hamari, 2019; Dichev \& Dicheva, 2017).

According to the framework developed by Werbach and Hunter (2012), when gamifying learning instructions, the components that must be included in the 'game' (typically, points, badges, leaderboards (PBL), levels (Hamari, Koivisto \& Sarsa 2014; Dichev \& Dicheva, 2017; Zainuddin, Chu, Shujahat \& Perera, 2020) need to be related to the intention and purpose of instruction, the needs of the target user group, but also the dynamics of a specific learning approach and capabilities of involved software tools. In gamification parlance, mechanics are concepts that define potential actions that the users can take while playing, especially guidelines that define how the game evolves, the possible reactions to an occurring event and what influences the users' reactions (feedback, collaboration, competition, etc.). Finally, specific game dynamics result from behaviours and interactions among users that are being stimulated by the components and mechanics described. The dynamic depends on each user's nature, personality and experience (Manzano-León, Camacho-Lazarraga, Guerrero, Guerrero-Puerta, Aguilar-Parra, Trigueros \& Alias, 2021; Werbach \& Hunter, 2012).

When gamifications goes beyond PBL, it follows a video-game design process (Manzano-León et al., 2021). The Mechanics, Dynamics, Aesthetics (MDA) model, developed by Hunicke, Le Blanc \& Zubek (2004), builds game aesthetics, on top of previously described principles of game mechanics and dynamics. As such, aesthetics involves specific emotional experience resulting from gameplay, such as fantasy, narrative, challenge, discovery, etc. (Hunicke et al., 2004). Adding one informal rule by a group of users allows transforming gamification into a complete game (Deterding, Khaled, et al., 
2011).

The combination of game components will trigger the desired learning behaviour, depending on the users' characteristics, such as age (Armier et al., 2016), educational (Morris et al., 2019) and skill level (Armier et al., 2016, Auvinen et al., 2015; De Pontes et al., 2019), learning (Armier et al., 2016; Chen \& Chiou, 2014; Fan, Xiao \& Su, 2015; Jiménez-Hernández et al., 2020) and gaming style (Bartle, 2005; Chapman \& Rich, 2017; Chou, 2016; Diamond et al., 2015; Hamari \& Tuunanen, 2014) and habits (Jaftha, Morone-Pinto \& Chircop, 2020; Preist \& Jones, 2015; Landers \& Armstrong, 2017) but also, cultural and generational norms (Armier et al., 2016).

Gamified systems that help users find their own reasons for engaging in targeted behaviour are known as meaningful gamification (Nicholson, 2014). This type of gamification is grounded in the self-determination theory of Ryan and Deci (2000), which implies that intrinsic motivation is driven by autonomy, competence or mastery and relatedness. Although simply rewarding a new behaviour may reinforce it and help develop an expected habit (Skinner, 1953), performing tasks for intrinsic reasons puts someone in a healthier mental state than performing tasks for extrinsic rewards (Nicholson, 2014). Furthermore, in order to achieve a desired effect on learning when incorporating games and game elements in learning instruction, a comprehensive, instructional design is required (Huang, Ritzhaupt, Sommer, Zhu, Stephen, Valle, Hampton \& Li, 2020; Landers, 2014; Fan, Xiao \& Su, 2015).

When not adjusted to users' attributes, gamification in education can create needless cognitive load, namely elements that are not necessary in instructional design have a tendency to burden working memory capacity by increasing extraneous levels of cognitive load (Sweller, 1988; Sweller, van Merriënboer, Jeroen \& Paas, 2019). For example, PBL have the potential to spark intrinsic motivation, but this may not always improve learning objectives (LOs), because these elements may trigger an unnecessary cognitive load. As a result, learners may be very cognitively engaged, but their attention may be drawn away from the learning task (Brom, Stárková, Bromová \& Děchtěrenko, 2019).

Hamari, Koivisto, and Sarsa (2014) stress that there is a lack of clear understanding about what kind of outcome is expected when specific methods are applied in a specific context, for instance which specific factor triggered better performance, the learning approach, gamified pedagogy or a specific type of interaction (Mese \& Dursun, 2019; Dichev \& Dicheva, 2017). There is an evident need for more empirical studies with well-designed methodologies and robust comparison groups in order to confirm the effectiveness of gamified learning (Hamari et al., 2014). This systematic review (SR) explores the effects of gamified instruction(Note 1) (GI) on students' LO with the aim of identifying what constitutes success or the lack thereof in the given context.

In the context that allows monitoring students engagement and learning progress during the course of an intervention, the pre and post-intervention testing discrepancy does not seem sufficient to understand the causality behind the phenomenon. While it is somewhat 'clearer' what is the minimum standard when learning progress is measured and what is missing in the current practice, the multitude of theories that provide gamification design rationale, call for 
the creation of minimum standards when reporting on the impact of GI on students' learning (Reeves \& Reeves, 2015). With this in mind, the main research question for this study is: 'How did the authors measure success of GI?'. The secondary research questions are: (i) 'What is the impact of a GI on students' engagement?', and, (iii) 'What is the impact of a GI on students' learning achievement?'. Both secondary research questions are discussed from the angle of the context in which the studies included in this SR took place.

\section{Research Methodology}

A SR of recent literature has been carried out in order to answer the research questions, with the focus lying on research situated within an educational setting. The review incorporates works indexed in the following digital libraries and databases: Education Resources Information Centre (ERIC), AIS eLibrary, ACM Digital Library, IEEE Xplore, Science Direct (Elsevier), Wiley Online Library, Springerlink, Ebsco, Emerald and the Directory of Open Access Journals (DOJ). In order to minimise the risk of biasing the results with data from unreliable sources, the non-peer-reviewed material was omitted and only peer reviewed literature was included in the search to ensure the quality of the results for the systematic review.

\subsection{Research Selection}

The literature review was carried out between October 2019 and December 2020. The final dataset is comprised of journal articles focusing on games, gamification, learning or education in their title and/or abstract that were published between January 2012 and December 2020. Study selection followed the protocol set out by Briffa, Jaftha, Loreto, Morone Pinto \& Chircop (2020), by which the selection process includes three levels of search criteria and a rigid set of inclusion and exclusion criteria. At first, researchers worked independently, screening the search results according to a number of defined criteria. Afterwards, they collaborated, removing duplicates from the list of selected studies as well as refining the list. Methodology and results of each contested study were examined until researchers reached a consensus what should or should not go into the list.

\subsection{Assessment Criteria and Extraction}

To make sure that the studies on the list were chosen as objectively as possible, three levels of specificity using certain keywords were identified. These were 'gamification' (Level 1), 'gamification and education' (Level 2), and 'gamification, education and control' (Level 3). This made each level more specific and better targeted to meet the necessary criteria. The remaining articles were filtered through an extra set of inclusion and exclusion criteria that followed the same profile as the study carried out previously (Briffa et al., 2020), with the exception of the articles reporting on studies that were implemented in post-graduate contexts being disregarded.

The included articles had to comply with the study objective by employing game or game-elements within an education setting; they had to be empirical ones using specific study 


\section{Macrothink

designs, such as triangulation or a quantitative analytic approach; they had to have an age restriction not permitting participants to be less than 11 years old; they had to systematically measure students' achievement and/or engagement and student perceptions of GI through tests and/or surveys and questionnaires; they had to report on studies that had involved an 'experiment' and a 'control' group, and, lastly, the articles chosen had to be available in full-text, in English and peer reviewed to ensure that they are of a high quality. Meanwhile, the articles not to be included were review articles, meta-analyses and systematic reviews (though these were used for cross-validation purposes) and articles which did not use game-based learning tools.

Note-worthily, the decision regarding the bottom age of participants was based on Piaget's four stages of cognitive development. Namely, at about age 11, the concrete operational stage ought to finish and youngsters enter the abstract operational stage when they start developing their abstract thinking capabilities (Inhelder \& Piaget, 2013). Therefore, it is both challenging and developmentally inappropriate to ask children below this age to reflect on their cognition (Fredricks, Blumenfeld \& Paris, 2004; Fredricks \& McColskey, 2012; Rodríguez, Puig, Tellols \& Samsó, 2020).

\subsection{Data Collection}

Application of the levels of search queries produced a total of 12,261 articles, published in the period 2012-2020. Duplicates were removed during the screening process. Whenever a full article was not initially available, authors were contacted via the academic social network 'ResearchGate' and a full version of the article was requested and another 14 articles were identified through alternative sources. A total of 12,275 were then screened thoroughly against the inclusion and exclusion criteria and a total of 12,152 articles were discarded due to not meeting the pre-determined requirements. One-hundred-twenty-tree full-text articles were assessed for eligibility and 51 further articles were dismissed because they reported on an experiment that: (10) involved a population below 11 years of age, (14) did not involve a control group/the control group involved was not compatible with researchers' expectations; (2) with vague methodology; (11) did not fit the purpose of the review; (3) involved students at a Post-Graduate level; (1) was also incorporated in another article; an article could not be accessed (1) as full text; (2) could not be accessed in English or an article (7) was not available. 


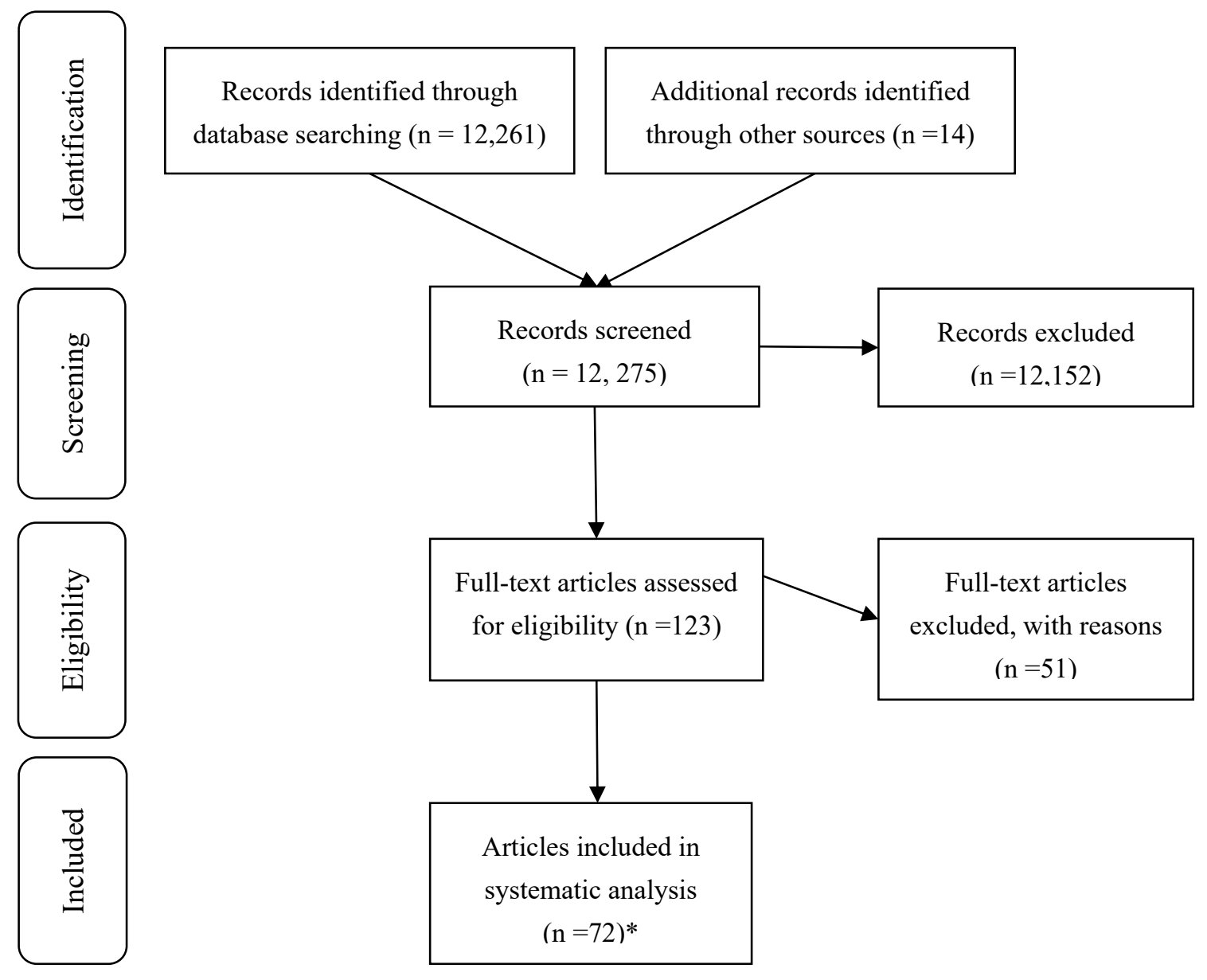

Figure 1. PRISM Flow Diagram. Image adopted from Moher, Liberati, Tetzlaff and Altman (2009)

Note* three articles in this review, report on two studies, where the data gathering mechanism was altered between the studies. Therefore, the total number of studies included in this review is 75. The articles included in this systematic review are marked with an asterisk in the References section.

\subsection{Data Analysis}

The data were organised and tabulated following the guidelines of Webster \& Watson (2002). According to these authors, to analyse studies for a review, a two-step process must be followed. The first step is an author-centric analysis in which selected studies are listed in a table and selected details from these papers are extracted and outlined in different columns. For this review, the details included: title of the article, journal and year of publication, educational level, subject, learning approach, game delivery platform, type of GI, game elements, sample size, gender representation within the sample, study duration and data collection tools. The second stage is a concept-centric method in which the author-centric analysis was pivoted and coded into concept-centric frequency tables (Webster \& Watson, 2002). 
Further analysis was guided by the following categories:

1. Intervention design

2. Engagement

3. Learning achievement

For category one, the following subcategories were considered: (i) data collection instruments, (ii) study duration, (iii) sample size, and (iv) gender representation within the sample. When it comes to categories two and three, the subcategories were: (i) subject, (ii) educational level, (iii) learning approach, (iv) type of GI, (v) game elements, and (vi) game delivery platform. The results were presented in a quantitative way (frequency) and outcomes were analysed based on their experiential and instrumental dimension (Liu et al., 2017).

Afterwards, the results were interpreted from a qualitative aspect, which allowed integrating the outcomes found in the categories of analysis, according to the corresponding phenomenon. The aim was to understand the phenomenon based on the qualities of the context, in order to clarify possible contradictions and generate conclusions about the effects of GI on learning outcomes.

\section{Results}

The search process resulted in 72 relevant articles which were included in the SR. The selected studies were journal articles $(62,84.9 \%)$ and conference papers $(11,15.1 \%)$.(Note 2) The majority of studies $(43,71.7 \%)$ explored the impact that GI has on both students' engagement and learning achievement. In addition, 16 (26.7\%) studies were only focused on engagement, while, in $12(20 \%)$ studies, learning achievement was solely the focus.

The studies included mainly involve the following structure for data gathering: first, the sample was split in one or (less often) more experiment groups and, most often, one control group. Most of the time, participants were randomly distributed into a control and an experiment group, unless the scope of the study also involved a particular learner characteristic in relation to the gamified instruction, such as learning style or gaming experience, for example. In that case, participants filled in a background questionnaire as part of the pre-test.

The experiment groups utilised gamified pedagogy and, most of the time, some kind of usage data was gathered; in case of two treatment groups they usually differed regarding the learning strategy (Sun-Lin \& Chiou, 2017), learning approach (Lam, Hew \& Chiu, 2018) or game-delivery platform (De-Marcos, Dominguez, Saenz-De-Navarrete \& Pages et al. 2014; Sun \& Hsieh, 2018). Furthermore, the control group(s) were mainly taught in a traditional manner, except in those studies that explored the impact of different designs ( $\mathrm{Wu}, 2018$; Muñoz-Carpio et al., 2019) or form of technology support (Naik \& Kamat, 2016) on students' learning outcomes.

In a small number of studies that involved two experiment groups, the control group was 
taught in a traditional manner, while experiment groups utilised different types of GI (Haruna, $\mathrm{Hu}, \mathrm{Chu}$, Mellecker, Gabriel \& Ndekao, 2018), game elements (Morris, Dragovich, Todaro \& Balci, 2019) or were taught via non/gamified versions of an alternative learning approach (Lam, Hew \& Chiu, 2018; Sun-Lin \& Chiou, 2017; Ferriz-Valero, Østerlie, Martínez \& García-Jaén, 2020).

\subsection{Intervention Design}

Selected studies greatly differed regarding the extent of data gathering and analysis, sample size and length of intervention. Those studies that focused on the impact of GI on students' engagement predominantly utilised only one $(23,35.9 \%)$ or two $(21,32.8 \%)$ data-gathering tools within these sources: game scoring (number of collected points/badges or completed/bonus tasks) and embedded data collection mechanisms (number of contributions or material views/downloads) $(36,56.2 \%)$; curricular means and attendance/retention rates (12, 23.1\%); qualitative data gathering techniques $(27,51.9 \%)$ and questionnaires created/adapted for the purpose of the study $(57,89.1 \%)$. The latter were self-report questionnaires aiming to explore the impact of GI on various constructs of motivation and engagement. Only in eight studies participants had the opportunity to fill in the questionnaires during the course of the intervention $(12.5 \%)$.

In order to measure the impact of GI on learning achievement, the studies included in this review predominantly utilised one $(38,63.3 \%)$ or two $(14,23.33 \%)$ data-gathering tools within the following sources, tests specifically designed/adapted for the purpose of the study $(40,67 \%)$ or curricular means $(31,52 \%)$. In addition, game scoring $(5,7 \%)$ and qualitative data-gathering techniques $(3,5.9 \%)$ were found in a small share of studies. Moreover, 16 $(13.37 \%)$ studies included in this review did not utilise, at any time during the intervention, tests that were adapted/created for the purpose of the study. Also, only two (4\%) studies explored knowledge retention rates with one of them not involving a post-test.

The following characteristics of the study design were also included in the analysis: sample size, intervention duration and gender representation within the sample.

Studies that include a small number of participants tend to generate findings that are context-dependent (Slavin \& Smith, 2009). Also, the presence of an experimental group requires a substantial sample size (Petri \& von Wangenheim, 2016). For this reason, studies were categorised using the following sample size indicators by Slavin and Smith (2009): $(\mathrm{N}<100)$ 'small sample size', $(100 \leq \mathrm{N}>250)$ 'medium sample size', and $(\mathrm{N}>250)$ 'large sample size' studies. In addition, in $29(38.2 \%)$ studies, gender representation within the sample was not reported. 


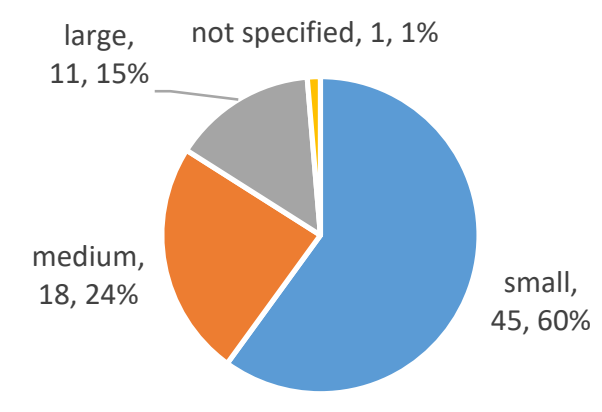

Figure 2. Sample Size in the Studies Included in the Review

Interventions of a short duration have a tendency to generate findings that are tempered by the gamification novelty effect. Namely, changes in users' behaviour may result from their curiosity about gamification and interest to try it out. Later on, as novelty wears off, these changed behaviour levels may decline (Chen, Shih \& Law, 2020; De-Marcos et al., 2014; Fotaris, Mastoras, Leinfellner \& Rosunally, 2016; Kermek, Novak, \& Kaniski, 2018; Liu, Santhanam \& Webster, 2017; Pechenkina et al., 2017; Tsay, Kofinas \& Luo, 2018; Zainuddin, Chu et al., 2020; Tsay, Kofinas, Smita \& Yang, 2020). As only 22 (29.3\%) studies included in this review report the length of intervention in hours (whether cumulative or distributed), studies that reported on interventions that lasted only one session were labelled as 'very short' and interventions that lasted for one week were labelled as 'short'. Meanwhile, interventions that spanned over one semester were labelled as 'medium' and those that took longer than one semester as 'long'.

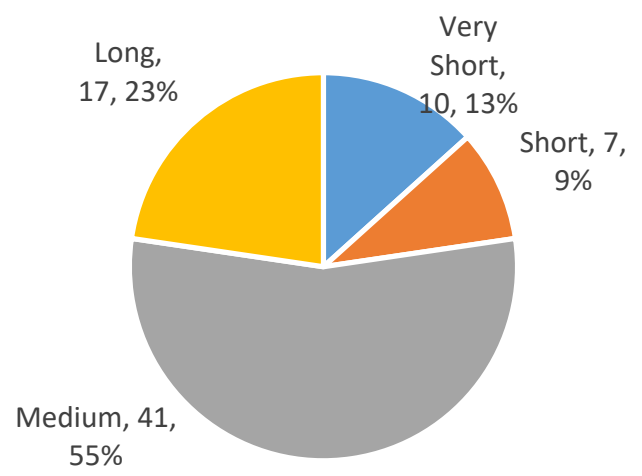

Figure 3. Intervention Duration in the Studies Included in the Review

A comprehensive description of the methodology and study design is a condition sine qua non for a critical evaluation of results obtained through experimental studies via means of replication studies (Reeves \& Reeves, 2015). 


\subsection{Context of Instruction}

In order to systematically describe the context in which these studies took place, the authors considered the participants' level of education, the subject being taught, the learning approach, the type of GI, the game elements and the game delivery platform. For a full list of articles including the type of GI, game elements used and the study outcome, see ANNEX B, Summary, Table 4.

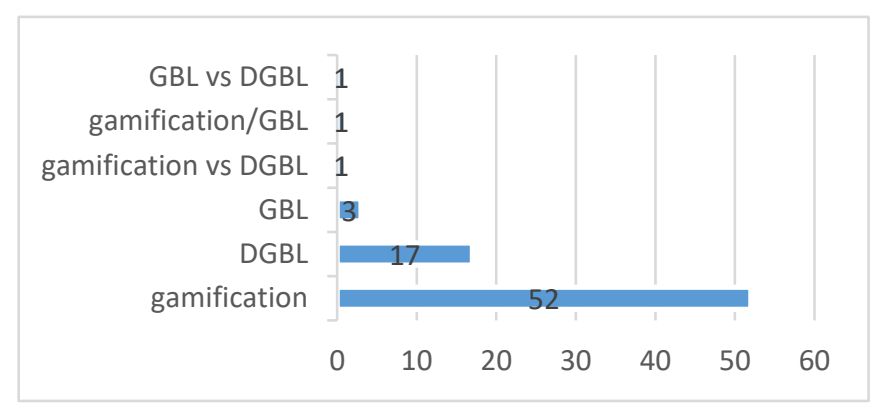

Figure 4. The Type of Gamified Learning Instruction

Note* GBL (Game-Based Learning without a digital dimension); DGBL (Digital Game-Based Learning)

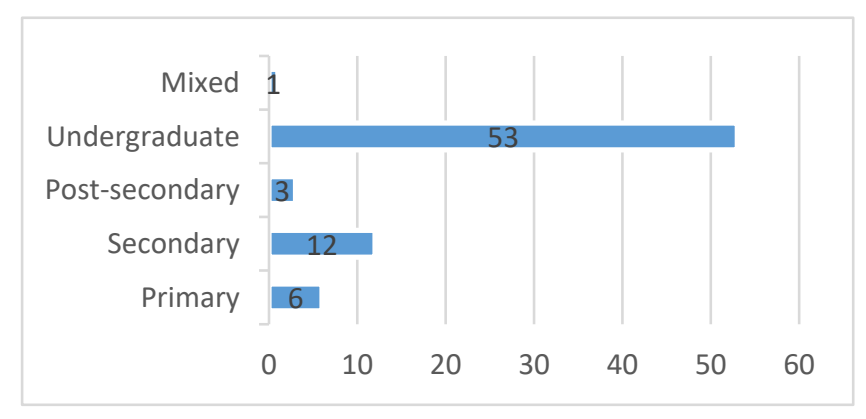

Figure 5. Participants' Level of Education

When it comes to the subject taught, the greatest share of included studies involved IT (22, $22.29 \%)$ and specific skills $(9,12.2 \%)$ such as library instruction or designing a questionnaire, followed by science, languages and mathematics ( $8,0.7 \%$ each), business and mixed subjects (both 4, 5.3\%). For more details, see Figure 6. 


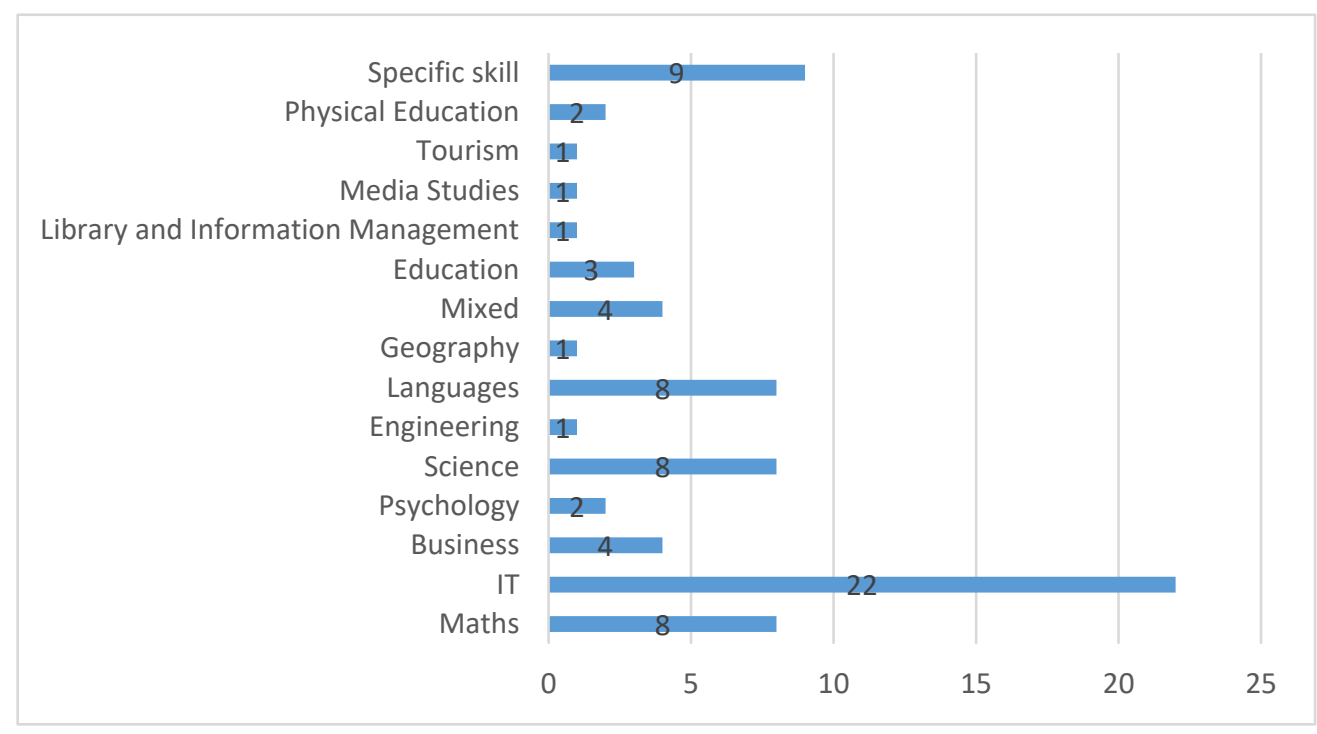

Figure 6. Subjects Gamified in the Studies Included in the Review

The majority of studies included in the review involved classroom-based instruction, whereas the role of the teacher was not limited only to the central figure in knowledge transmission. Unless the authors specified the approach or the description of the activities did not imply otherwise, these studies were labelled as the traditional learning approach $(22,29.3 \%)$, followed by a flipped classroom, $(13,17.3 \%)$ and blended learning approach $(10,13.4 \%)$. For more details, see Figure 7.

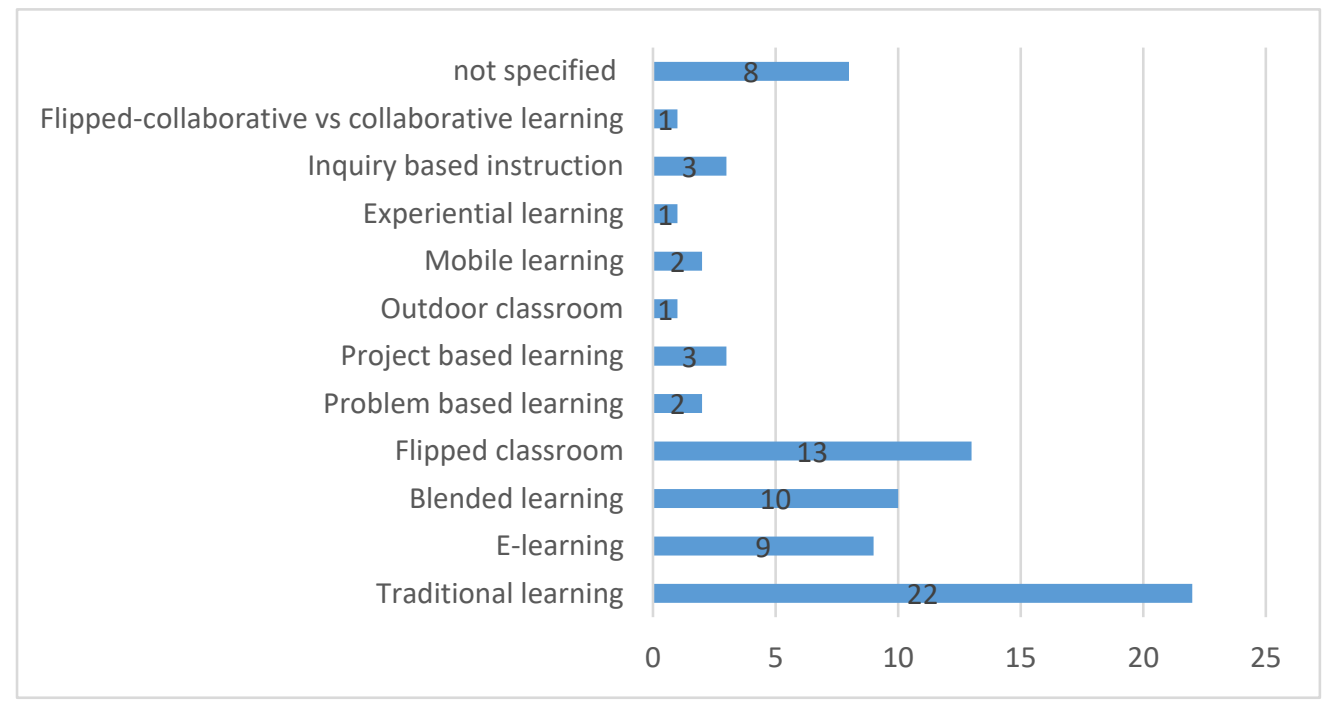

Figure 7. Learning Approach in the Studies Included in the Review

Among the studies included in the review, the most usually employed game delivery platform was the virtual learning environment (VLE) (22, 29.3\%), followed by web-based content (14, 18.7\%). The latter includes online learning platforms like TRAKLA2, MinecratfEdu, etc., 
and cases where game element was delivered in a web-based format (e.g. website served as a LB). Furthermore, a number of studies $(12,16 \%)$ utilised a platform configured of two or more previously mentioned platforms, such as IRS/game mechanics, VLE/DGBL or DGBL/IRS/VLE that were all used in two $(2.7 \%)$ studies each. For more details, see Figure 8. In addition, in $37(49.3 \%)$ studies, platforms were developed specifically for the purpose of that specific research while seven $(9.7 \%)$ studies were utilising a system configured of components that were at least partly already available on the market.

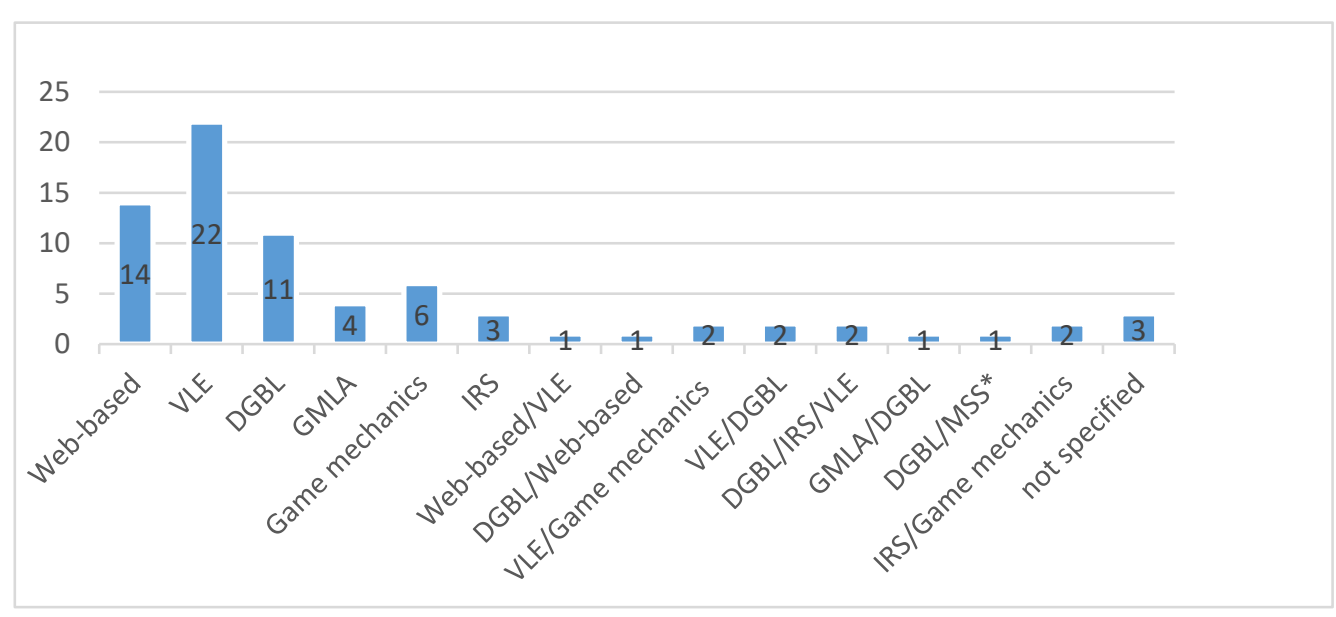

Note* MSS (Motion Sensing System)

Figure 8. Game Delivery Platform in the Studies Included in the Review

When it comes to the description of game elements, the level of detail varied greatly among the studies. For this reason, the data on game elements was first listed as specified in the articles. Afterwards, researchers replaced synonyms so that uniform language is used and frequency of usage could be calculated for each game element. Moreover, six (8\%) studies did not include a description on game elements. For more details, see Figure 9.

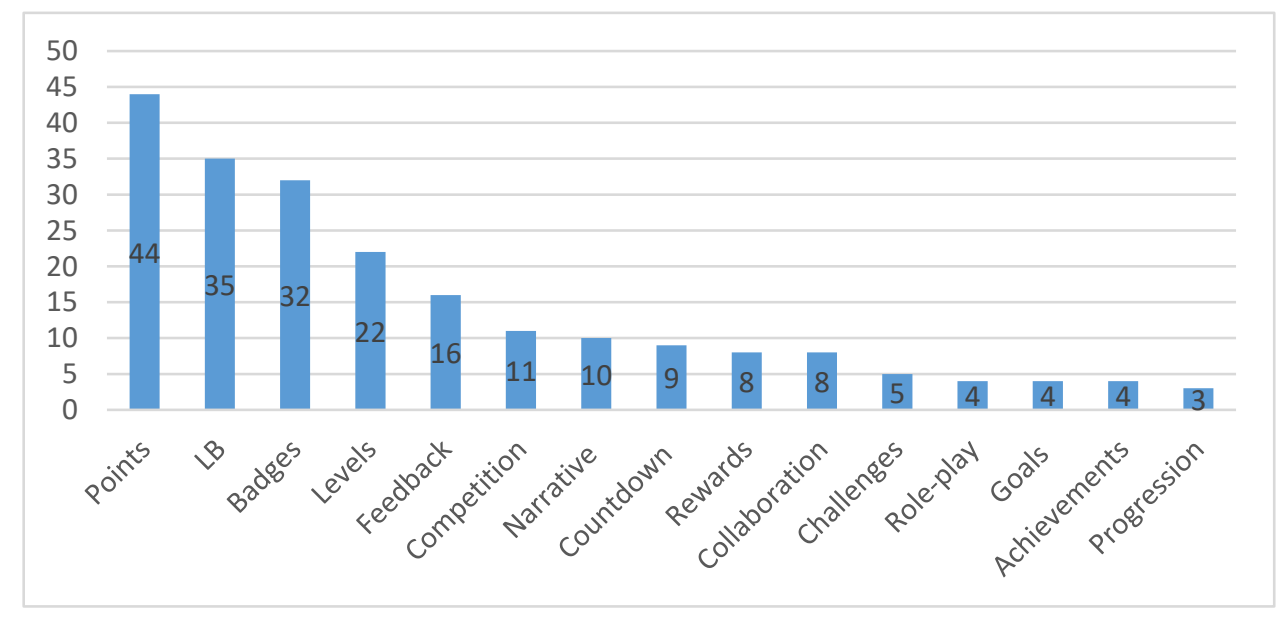

Figure 9. The Most Commonly Used Game Features in the Studies Included in the Review 
Based on their outcomes, studies were grouped into categories (listed below) that display varying positive effects on GI (i-iii) and possible failure to improve GI (iv):

I. the majority of measured aspects of: a) engagement $(37,57.8 \%)$, and/or b) academic achievement $(31,51.7 \%)$

II. only one aspect of a) engagement $(15,23.4 \%)$; and/or b) academic achievement $(9,15 \%)$ that was measured

III. on a) engagement $(6,9.4 \%)$, and/or b) academic achievement $(5,8.3 \%)$ of only a specific subpopulation (e.g. male/female participants, high/low achievers, etc.); and

IV. studies that failed to identify a significant positive effect of GI on any aspect of a) engagement $(6,9.4 \%)$ and/or b) academic achievement $(15,25 \%)$ that was measured.

\section{Discussion}

\subsection{Intervention Design and Reported Learning Outcomes}

If we take into consideration the practice of diverse, and often unstated, rationale for different gamification designs (Seaborn \& Fels, 2015; Dichev \& Dicheva, 2017) it is understandable that the designs, methods, and variables that were explored in the studies included in this review vary substantially (Manzano-León et al., 2021). This subjective and unsystematic practice leaves some theories, relevant factors and forms of engagement in gamified learning environment underexplored and without a theory-derived framework to scaffold gamification design (Rapp et al., 2019; Dichev \& Dicheva, 2017; Nacke \& Deterding, 2017; Seaborn \& Fels, 2015; Deterding et al., 2011).

In 2011, Deterding, Khaled, et al. proposed a working definition for the group of phenomena that gamification represents, including similar concepts like serious games, serious gaming, etc. as "the use of game design elements in non-game contexts." (p. 1). In order to precisely integrate a variety of research endeavours, the authors suggest involving the description of the following levels of game-design process: interface design patterns-game components used to create interfaces for the specific context that users face; game design patterns/game mechanics - reoccurring blocks of game design that dictate the game play; design principles or heuristics: rules for approaching a design problem/evaluating a design solution.; and conceptual models of game components/game experience, such as the MDA (Deterding, Khaled, et al., 2011).

Aside from the sporadic and scarce description of game components, among the studies included in the review, information that was the most often lacking was the gender representation within the sample (Torres-Toukoumidis et al., 2021) as $38.16 \%$ of reviewed studies did not include this information and the length of intervention expressed in hours, that was included only in $29.3 \%$ of the studies. Furthermore, in a number of studies, the authors did not specify the learning approach used to deliver GI. Still, based on the description of learning activities, these studies were labelled as taking place in a traditional classroom but, in $10.7 \%$ of studies, there was no notion of the learning approach used and, in $4 \%$ of the studies, the 
delivery platform was not specified. This leaves an impression that the importance of a comprehensive instructional design is not being stressed enough and that the mentality of putting technology first is still present in academia. A theoretical model that links the learning approach used to deliver the GI with the outcomes of the intervention is a precondition in order to detangle why these techniques affect outcomes the way they do. The present gap not only restricts the generalisability of research findings but also, provides unreliable guidance to gamification practitioners (Landers, 2014). The motivational effect triggered by a specific mechanism is not guaranteed in a different educational context (Dichev \& Dicheva, 2017).

More than half of the studies that explored the effect of GI on learning achievement $(63.3 \%)$ based their conclusions on data collected via only one data-collection source, predominantly pre and post-tests developed or adapted for the purpose of the study (26\%). In addition, 5.2\% of these studies did not gather any data on students' engagement. Although the difference between pre- and post-testing is a sound proof of the progress made, grades and test scores alone do not say much about the quality of the effort exerted in order to obtain them. Likewise, data obtained via embedded data-collection mechanisms, game scoring, curricular means and students' attendance rates alone do not record changes in motivation $(7.8 \%$ of included studies explore the effect on students' engagement only via these data collection sources).

The students' voice needs to be heard as, otherwise, the human side of the gamified experience will go unnoticed. Also, when aiming to aptly categorise and interpret the effects of GI, attitudes and behaviours that are the direct outcome of GI should be explicitly measured (Landers, 2014). Among included studies with learning achievement in focus, only 5\% involved qualitative data-collection techniques. A number of authors recommend exploring the topic via a mixed-method approach (Alt \& Raichel, 2020; Segura-Robles et al., 2020; Aşıksoy, 2018; Hew et al., 2016; Huang et al., 2019b; Ortiz-Rojas, Chiluiza \& Valcke, 2019; Torres-Toukoumidis et al., 2021; Wichadee \& Pattanapichet, 2018). Specifically, involving more interview data in addition to the data collected via quantitative means (Aş1ksoy, 2018; Hew et al., 2016; Huang et al., 2019; Ortiz-Rojas, Chiluiza, \& Valcke, 2019; Wichadee \& Pattanapichet, 2018) and triangulating the data collected via self-report questionnaires or qualitative techniques with the observational data would be a good idea (Segura-Robles et al., 2020; Alt \& Raichel, 2020).

Continuous theoretical and rigorous systematic empirical work in varying gamification settings and contexts is a prerequisite for developing a comprehensive practical and methodological understanding of the benefits of GI (Dichev \& Dicheva, 2017). Still, Rapp et al. (2019) warn that, so far, very little empirical work has focused on exploring the influence of contextual factors and individual diversities on the effectiveness of gamified systems. Therefore, aside from a mixed-method approach, a detailed description of the game-design process, future studies should involve a detailed description of the context in which they took place. In addition, those studies that are utilising a game already available on the market (instead of developing one), ought to list the game components.

A description of the study context has multiple purposes, such as to systematically organise research findings, recognise the variant effect on different sub-populations and suggest the way 
forward when designing and implementing GI within specific conditions. Therefore, the description must depict the subject/topic of instruction and the educational level; the learning approach and the platform used to deliver GI; and the characteristics of the sample, such as gender representation and participants' average age, and intervention duration expressed in hours instead of simply stating that the intervention spanned over a semester. In addition, considering the small number of interventions that took longer than one semester $(22.7 \%)$; included subsequent $(5 \%)$ or delayed tests $(5 \%)$ and involved a sample of more than 250 participants (14.7\%). In order to understand how students approach GI and mis/use it, future studies should be longitudinal (B. Huang et al., 2018; Van Roy, Deterding \& Zaman, 2018) or at least involve a longer duration, a larger number of participants and a more intensive progress tracking schedule.

\subsection{Learning Context and Learning Outcomes}

In general, in gamification research, the majority of studies so far have involved college students (Dichev \& Dicheva, 2017) and GI of subjects under the IT umbrella, followed by engineering and mathematics (Swacha, 2021). Accordingly, the majority of studies included in the SR took place at undergraduate level (53), involved IT (22) and used VLE (22) for game delivery. Therefore, it does not come as a surprise that, from the aspect of individual subjects, all studies that reported a significant effect of GI on students' achievement and involved IT took place at undergraduate level (7). The majority of these studies utilised VLE (4) for delivery of GI and were framed in a blended framework (3).

The other two subjects where GI, most often, had significant impact on students' learning achievement were Mathematics (6) and Science (6). The majority of these studies took place at the primary (4) or secondary (4) level and employed DGBL (6) in a traditional (2) classroom. Note-worthily, gender differences seem to affect LOs when employing a DGBL approach (Dorji et al., 2015; Khan et al., 2017). Moreover, competition in DGBL was found to be effective when learning mathematics, science and languages, whereas the impact of competition on LOs varied due to game genre, subject, or grade level (Chen, Shih \& Law, 2020). In general, men experience greater success with gamification when it involves competition while, for women, the social aspect of gamification is crucial (Hamari et al., 2014). However, based on the available description of game components, regardless of the type of GI, it seems that studies that involved these three subjects and found significant effect of GI on student achievement predominantly combined competition and collaboration mechanics (Barlow \& Fleming, 2016; Gressick \& Langston, Aş1ksoy, 2018; Borsos, 2019).

In order to ensure the optimal effect of collaborative learning, a) the knowledge of group members should not be of the same level, instead, knowledge gaps should be present among members; b) the type of tasks should be of a problem-solving nature, and c) the learning strategy needs to be in line with the learners' level of expertise (Retnowati et al., 2018). Correspondingly, students reported that collaboration allowed them to build on each other's knowledge, develop new attitudes, cognitive and psychomotor skills (Dziob, 2020) but, also, gain confidence in their existing capabilities and stimulated them to apply the knowledge and skills learned in their place of work (Alt \& Raichel, 2020). In order to avoid collaboration 
creating an extraneous cognitive load that can reduce learning, learners need to perceive collaboration as necessary to achieve their learning goal (Chandler \& Sweller, 1991).

A number of studies did not find a detectable effect of GI on students' achievement $(15,25 \%)$ and/or engagement $(6,9.4 \%)$. Instead, some negative effects on participants' engagement relative to the control condition were identified, such as a decrease in motivation, satisfaction and empowerment over time (Hanus \& Fox, 2015). Some participants felt higher pressure, tension (Hong \& Masood, 2014) and anxiety (Aş1ksoy, 2018). The types of interactions that students have among themselves have a long-lasting effect on their LOs (Huang et al., 2020), therefore, the authors link this negative experience with the collaborative and competitive nature of GI (Hong \& Masood, 2014). Authors warn that gamification promotes individual work and competition over collaboration (De-Marcos et al., 2014) and, also, that competition might take priority over the urge to gain knowledge (Mese \& Dursun, 2019; De-Marcos et al., 2014). For this reason, Armier et al. (2016) recommend considering students' tendencies towards collaboration and competition prior to the intervention.

Over a half of studies (53\%) that found no significant effect of GI on students' learning achievement reported a significant positive effect on students' engagement. Though participants reported, predominantly, positive effects on their emotional engagement (Khan et al., 2017; Leaning, 2015; Rojas-López et al., 2019; Kaneko et al., 2016; Sancho-Vinuesa et al., 2018) and behavioural engagement (Khan et al., 2017; Laskowski, 2015), they also acknowledged the approach as relevant to grasp the content (Kaneko et al., 2016; Leaning, 2015; Stansbury \& Earnest, 2017) and beneficial in advancing their reasoning abilities (Stansbury \& Earnest, 2017). For this reason, Rojas-López et al. (2019) highlight, that cognitive assessment should not reside only on traditional assessment instruments (Dichev \& Dicheva, 2017). Instead, new instruments may shed light on qualities of engagement (De-Marcos et al., 2014) and learning (Mese \& Dursun, 2019) that were not accounted for. For example, Rojas-López et al. (2019) suggest including instruments for the evaluation of competitions such as the resolution of problems.

The majority of the above-mentioned studies, with conflicting findings, were framed in the traditional (Khan et al., 2017; Leaning, 2015; Stansbury \& Earnest, 2017) or e-learning context (Kaneko et al., 2016; Sancho-Vinuesa et al., 2018) and employed competition and progression components. The conflicting findings could be a result of the ill-fitted progress-tracking mechanism or, maybe, the different game components, such as collaboration and/or narrative, which might contribute more to students' learning in the given context. Also, it seems that, in a traditional classroom, DGBL has the greatest potential to improve students' engagement and achievement (García \& Cano, 2018; Hannig et al., 2013; Sun-Lin \& Chiou, 2017). Dichev and Dicheva (2017) presume that overemployment of PBL originates from their similarity to traditional classroom assessment.

In a distant learning environment, interactivity is crucial for building and maintaining personal relationships and a sense of belonging in the community (Delahunty, Verenikina, \& Jones, 2014). Game elements, such as points, sharing virtual goods/gifts, team LB, social graphs and an option to comment on the activity of one's peer learners, have potential to 
promote social interaction and a sense of community in this context (Zainuddin, Chu, et al., 2020). De-Marcos et al. (2014) found that, in an e-learning context, social networking had greater impact on students' participation rates and knowledge acquisition than the GI, whereas Huang et al. (2020) found positive effects of GI on students' online interaction. In order to make students more relaxed to express their views, some authors propose allowing them to stay anonymous (Lam et al., 2018; Rojas-López et al., 2019) also, anonymity can prevent students from using other channels of communication than those offered as a part of the system (Berns et al., 2016). Gamification is particularly suitable for learning approaches in which students, through experiential learning and active interaction among themselves, construct a LO (Cheong et al., 2014; Caton \& Greenhill, 2014; Tsay et al., 2018).

In a number of studies that utilised a competitive game-based approach in a hybrid setting, participants reported that their motivation and engagement had improved (Aşıksoy, 2018; Rojas-López et al., 2019; Wang, 2017; Zainuddin, 2018, Tsay et al., 2020) along with, their reasoning skills (Zainuddin, 2018), IT competencies and learning capacity (Zainuddin, 2018; Zainuddin, Chu, et al., 2020; Huesca Juárez \& Medina Herrera, 2019). Furthermore, participants reported that the approach promoted exchange of ideas, discussion, social learning (Aş1ksoy, 2018; Wang, 2017) and completion of challenges (Rojas-López et al., 2019). The majority of these studies utilised VLE (Aş1ksoy, 2018; Rojas-López et al., 2019; Zainuddin, 2018, Tsay et al., 2020).

In a hybrid setting where GI is delivered via VLE, game narrative (supported by game elements) proved to be a useful means to connect learning activities that are offered on the system (Tsay et al., 2020). In order to create the narrative, Tsay et al. (2020) had regular communication with students, carefully selected useful tasks and set clear rules. So, based on the communication with students, the authors included design choices that match a greater range of learners than in the first iteration and promoted only those activities that were the most popular, while the least popular activities were removed from the second iteration. This way, the narrative ensured the "meaningfulness" that students needed to overcome the novelty effect (Tsay et al., 2020).

Interventions that were delivered via inquiry-based (Diez-Pascual, 2020, Morillas Barrio et al., 2016; Sun-Lin \& Chiou, 2019) and problem-based learning (Caton \& Greenhill, 2014, Alt \& Rachel, 2020) often reported very similar effects of GI on students' achievement (as hybrid setting) including, significantly, higher grades (Díez-Pascual \& García Díaz, 2020; Caton \& Greenhill, 2014), higher number of students who passed the exam in the first take (Díez-Pascual \& García Díaz, 2020), higher quality of output (Caton \& Greenhill, 2014), advancement of reasoning abilities (Sun-Lin \& Chiou, 2019) and creative capacity (Alt \& Raichel, 2020). The majority (4) of these studies involved participants at undergraduate level and gamified content was delivered through a variety of platforms, including combined ones, but none of them utilised VLE.

Although teacher-learner communication via IRS remains unidirectional (Sun \& Hsieh, 2018), continuous monitoring delivered by this tool enables students to self-regulate their progress, and promotes autonomy and control of their own learning (González, 2018; Zainuddin, Shujahat, Haruna \& Chu, 2020). The main challenge of inquiry-based instruction is that 
cognitive gain is only as strong as the questions asked (Morillas Barrio et al., 2016). When it comes to specific sub-populations, the use of IRS seemed to have the greatest effect on learning achievement of medium (Wang, 2017) and low achievers (Wu, 2018; González, 2018), young (Wang, 2017; González, 2018) and novice learners (Wang, 2017), whereas male students favoured the use of IRS more than female (Khan et al., 2017).

\section{Conclusion}

Before concluding the findings of this review, it is important to stress that the research included only listed libraries and databases. Therefore, it is likely that relevant articles that were published in the journals not included in these sources were omitted. For this reason, future reviews should involve a wider range of both libraries and sources. In addition, due to the main focus of studies included in the review, this study was not able to answer the question 'What are the limitations of GI?'. Hence, aside from the recommendations listed below, future studies should focus more on the link between specific game element/game mechanics and unintended consequences of design that may lead to adverse effects.

If the aim is to understand when and why gamified learning fails, it seems artificial and incomplete to explore learning progress in isolation from the other dimensions of experience that accompany it. Among the studies included in this review, primary deficiencies involve sporadic description of game design process/game components, scarce descriptions of study contexts, a lack of mixed-methods approaches, small numbers of participants and short intervention durations. Evidently, gamification is moving away from the typical use of PBLs and, therefore, relies more on established game-design principals (Manzano-León et al., 2021; Rapp et al., 2019). Still, for some reason, it seems that gamification research neglects the full range of game design expertise when designing a system (Rapp et al., 2019).

Defining essential variables and the creation of minimum standards in educational research communities is vital because it allows the systemising of findings resulting from diverse research attempts but, also, the filtering of a variety of findings in the field via means of replication studies (Reeves \& Reeves, 2015). For this reason, future studies should include a description of the subject/topic; learning approach and delivery platform; characteristics of the sample and intervention duration expressed in hours. Moreover, studies that developed their own 'games' should include the description of the game design process or, if utilising a 'game' already available on the market, a detailed list of game components should be provided. In order to obtain more in-depth findings, it is highly recommended to use a mixed-methods approach, with a more intense tracking schedule, including modern assessment instruments and a longitudinal study design.

The effect that GI has on students' LOs largely depends on linking the appropriate learning approach (one that facilitates development of skills needed to competently apply the content of instruction and complete the 'game') with optimal delivery platform. That is, a platform, or a combination of platforms, that support game-like features and types of interaction that prove to stimulate motivation and learning engagement of a specific student population in a 
given context. For example, in hybrid settings, the greatest success was linked with the use of VLE, but, when it comes to question-driven instructions or project/problem-based learning, combined platforms or IRS were utilised. On the other hand, unlike the hybrid pedagogy where learning content, regardless of learners' age, can be tailored for asynchronous learning, active learning approaches require a developed capacity for abstract thinking/level of cognitive maturity.

Clearly, the magnitude of the impact is not in the learning technology but in the type of interaction (Beauchamp \& Kennewell, 2010). Classroom interaction typically ranges from 'authoritative' to 'dialogic' and shifting towards the dialogic end of the scale should result in improved learning processes and outcomes (Beauchamp \& Kennewell, 2010). While a specific learning approach dictates the dynamic of learner-teacher interaction, the components that are included in the platform dictate how learners will interact among themselves and progress through the game (Armier et al., 2016; Tsay et al., 2020).

In general, when teachers first adopt learning technologies as a part of their practice, there is a trend that interactivity is superficial and more on the authoritative side (Beauchamp \& Kennewell, 2010). For this reason, future educators should be trained both in a variety of innovative methods and instructional pedagogies including GI (Camilleri \& Camilleri, 2019; Gressick \& Langston, 2017) and the latest IT trends (Ahmadi, 2018; Zainuddin, Chu et al., 2020). In addition, gaining experience in implementing GBL without the use of technology seems a good way to feel the 'classroom dynamics' when specific game mechanics are introduced (Zainuddin, Chu, et al., 2020). When it comes to 'game' rules and guidelines, it is a must to keep them clear and simple (Armier et al., 2016; Kermek et al., 2018; Tsay et al., 2020).

Both user-centred design and student-centred learning place user/learner needs in the centre of an effective system (Hesson \& Shad, 2007). Well-designed interactive programmes allow students to see and explore concepts from different perspectives by using various representations of ideas, real-time feedback and opportunities to apply learning through content creation (Darling-Hammond, Zielezinski \& Shelly, 2014). In a gamified classroom, students feel in control of their learning because they can learn at their own pace, while the continuous feedback provides them with hints and opportunities for contemplation when facing a problem while practicing the curriculum (Rueckert et al., 2020).

\section{Acknowledgement and sponsoring information}

This paper is an extract from the work developed by the Gamification Research team at the Malta College of Arts, Science and Technology (MCAST). Further acknowledgment goes to Dr. Tatjana Chircop, MCAST Deputy Principal: Arts and Social Sciences-VPET and project leader "ESF.02.058 Adding Value: Nurturing Learning Journeys in IVET at MCAST", to The Malta College of Arts, Science and Technology (MCAST) as a project host institution, and to the European Union under the European Social Fund - European Structural and Investment Funds 2014-2020, for the financial support. 


\section{References}

*The articles included in this systematic review are marked with an asterisk.

Ahmadi, D. M. R. (2018). The Use of Technology in English Language Learning: A Literature Review. International Journal of Research in English Education, 3(2), 115-125. https://doi.org/10.29252/ijree.3.2.115

*Alhosseini, S. S. N., \& Ata, P. (2018). 'Earthquake in the City'; Using Real Life Gamification Model for Teaching Professional Commitment in High School Students. Journal of Medical Ethics and History of Medicine. PMCID: PMC6642457.

Aljraiwi, S. (2019). Effectiveness of Gamification of Web-Based Learning in Improving Academic Achievement and Creative Thinking among Primary School Students. International Journal of Education and Practice, 7(3), 242-257.

*Alt, D., \& Raichel, N. (2020). Enhancing perceived digital literacy skills and creative self-concept through gamified learning environments: Insights from a longitudinal study. International Journal of Educational Research, 101(January), 101561. https://doi.org/10.1016/j.ijer.2020.101561

*Armier, D. D., Shepherd, C. E., \& Skrabut, S. (2016). Using Game Elements to Increase Student Engagement in Course Assignments. College Teaching, 64(2), 64-72. https://doi.org/10.1080/87567555.2015.1094439

*Aşıksoy, G. (2018). The effects of the gamified flipped classroom environment (GFCE) on students' motivation, learning achievements and perception in a physics course. Quality and Quantity, 52, 129-145. https://doi.org/10.1007/s11135-017-0597-1

*Auvinen, T., Hakulinen, L., \& Malmi, L. (2015). Increasing Students' Awareness of Their Behavior in Online Learning Environments with Visualizations and Achievement Badges. IEEE Transactions on Learning Technologies. https://doi.org/10.1109/TLT.2015.2441718

*Barata, G., Sandra, G., Joaquim, J., \& Daniel, G. (2013). Improving Participation and Learning with Gamification. ACM International Conference Proceeding Series. https://doi.org/10.1145/2583008.2583010

*Barlow, T., \& Barry, F. (2016). A Science Classroom That's More than a Game. Teaching Science.

Bartle, R. (2005). Virtual Worlds: Why People Play. Massively Multiplayer Game Development, 2(2), 3-18. Retrieved from http://www.mud.co.uk/richard/VWWPP.pdf

Beauchamp, G., \& Kennewell, S. (2010). Interactivity in the classroom and its impact on $\begin{array}{llll}\text { learning. } \quad \text { Computers } & \text { 759-766. }\end{array}$ https://doi.org/10.1016/j.compedu.2009.09.033

Berns, A., Isla-Montes, J. L., Palomo-Duarte, M., \& Dodero, J. M. (2016). Motivation, students' needs and learning outcomes: a hybrid game-based app for enhanced language 
learning. SpringerPlus. https://doi.org/10.1186/s40064-016-2971-1

*Borsos, E. (2019). The gamification of elementary school biology: a case study on increasing understanding of plants. Journal of Biological Education, 53(5), 492-505. https://doi.org/10.1080/00219266.2018.1501407

Briffa, M., Jaftha, N., Loreto, G., Pinto, F. C. M., \& Chircop, T. (2020). Improved Students' Performance within Gamified Learning Environment: A Meta-Analysis Study. International Journal of Education and Research, 8(1), 223-244.

*Brom, C., Stárková, T., Bromová, E., \& Děchtěrenko, F. (2019). Gamifying a Simulation: Do a Game Goal, Choice, Points, and Praise Enhance Learning? Journal of Educational Computing Research, 57(6), 1575-1613. https://doi.org/10.1177/0735633118797330

*Buhagiar, T., \& Leo, C. (2018). Does Gamification Improve Academic Performance? Journal of Instructional Pedagogies, 20, 1-6.

Camilleri, M. A., \& Camilleri, A. C. (2019). Student-Centred Learning Through Serious Games. INTED2019 Proceedings. https://doi.org/10.21125/inted.2019.0578

*Caton, H., \& Greenhill, D. (2014). Rewards and penalties: A gamification approach for increasing attendance and engagement in an undergraduate computing module. International Journal of Game-Based Learning, 4(3), 1-12. https://doi.org/10.4018/ijgbl.2014070101

Chandler, P., \& Sweller, J. (1991). Cognitive Load Theory and the Format of Instruction. Cognition and Instruction, 8(4), 293-332. https://doi.org/10.1207/s1532690xci0804_2

Chapman, J. R., \& Rich, P. (2017). Identifying Motivational Styles in Educational Gamification. Proceedings of the 50th Hawaii International Conference on System Sciences, 1318-1327.

Chen, B. H., \& Chiou, H. H. (2014). Learning style, sense of community and learning effectiveness in hybrid learning environment. Interactive Learning Environments. https://doi.org/10.1080/10494820.2012.680971

Chen, C. H., Shih, C. C., \& Law, V. (2020). The effects of competition in digital game-based learning (DGBL): a meta-analysis. Educational Technology Research and Development. https://doi.org/10.1007/s11423-020-09794-1

Cheong, C., Filippou, J., \& Cheong, F. (2014). Towards the Gamification of Learning: Investigating Student Perceptions of Game Elements. Journal of Information Systems Education, 25(3), 233-244.

Chou, Y. (2016). Actionable gamification: Beyond points, badges, and leaderboards. In Octalysis Media. https://doi.org/10.1017/CBO9781107415324.004

*Chung-Shing, C., Yat-Hung, C., \& Heung Agnes, F. T. (2020). The effectiveness of online scenario game for ecotourism education from knowledge-attitude-usability dimensions. Journal of Hospitality, Leisure, Sport \& Tourism Education, 27, 
https://doi.org/10.1016/j.jhlste.2020.100264

Darling-Hammond, L., Zielezinski B. M., \& Shelly, G. (2014). Using Technology to Support At-Risk Students' Learning. In Using Technology to Support At-Risk Students 'Learning (Vol. 25, Issue September). Retrieved from http://www.uk.sagepub.com/books/Book242155/toc\%5Cnhttp://www.bookdepository.co $\mathrm{m} /$ Learning-Teaching-Development-Lyn-Ashmore/9781446282113

*De-Marcos, L., Domínguez, A., Saenz-De-Navarrete, J., \& Pagés, C. (2014). An empirical study comparing gamification and social networking on e-learning. Computers and Education, 75, 82-91. https://doi.org/10.1016/j.compedu.2014.01.012

*De Pontes, R. G., Medeiros, K. H. M., Guerrero, D. D. S., \& De Figueiredo, J. C. A. (2019). Analyzing the Impact of Leaderboards in Introductory Programming Courses' Short-Length Activities. Proceedings - Frontiers in Education Conference, FIE. https://doi.org/10.1109/FIE.2018.8658937

Delahunty, J., Verenikina, I., \& Jones, P. (2014). Socio-emotional connections: Identity, belonging and learning in online interactions. A literature review. Technology, Pedagogy and Education, 23(2). https://doi.org/10.1080/1475939X.2013.813405

*Denny, P. (2013). The Effect of Virtual Achievements on Student Engagement. Conference on Human Factors in Computing Systems - Proceedings.

Deterding, S., Dixon, D., Khaled, R., \& Nacke, L. (2011). From game design elements to gamefulness. From Game Design Elements to Gamefulness: Defining "Gamification”. Proceedings of the 15th International Academic MindTrek Conference on Envisioning Future Media Environments - MindTrek '11, 9. https://doi.org/10.1145/2181037.2181040

Deterding, S., Khaled, R., Nacke, L. E., \& Dixon, D. (2011). Gamification: Toward a Definition. Gamification Workshop. CHI 2011 Gamification Workshop Proceedings, January 2011, 12-15.

Diamond, L., Tondello, G. F., Marczewski, A., Nacke, L. E., \& Tscheligi, M. (2015). The HEXAD Gamification User Types Questionnaire: Background and Development Process. Workshop on Personalization in Serious and Persuasive Games and Gamified Interactions, October.

Dichev, C., \& Dicheva, D. (2017). Gamifying education: what is known, what is believed and what remains uncertain: a critical review. International Journal of Educational Technology in Higher Education. https://doi.org/10.1186/s41239-017-0042-5

*Díez-Pascual, A. M., \& García Díaz, M. P. (2020). Audience Response Software as a Learning Tool in University Courses. Education Sciences, 10(12). https://doi.org/10.3390/educsci10120350

Dorji, U., Panjaburee, P., \& Srisawasdi, N. (2015). Gender differences in students' learning achievements and awareness through residence energy saving game-based inquiry playing. Journal of Computers in Education, 2(2), 227-243. 
https://doi.org/10.1007/s40692-015-0033-2

Duin, H., Hauge, J. B., Hunecker, F., \& Thoben, K. D. (2011). Application of serious games in industrial contexts. Business, Technological, and Social Dimensions of Computer Games: Multidisciplinary Developments, January, 331-347. https://doi.org/10.4018/978-1-60960-567-4.ch020

Dziob, D. (2020). Board Game in Physics Classes - a Proposal for a New Method of Student Assessment. Research in Science Education, 50(3), 845-862. https://doi.org/10.1007/s11165-018-9714-y

*Ferriz-Valero, A., Osterile, O., Martinez, S. G., \& Garcia-Jaen, M. (2020). Gamification in Physical Education: Evaluation of Impact on Motivation and Academic Performance within Higher Education. International Journal of Environmental Research and Public Health, 17(12), 1-16. https://doi.org/10.3390/ijerph17124465

*Fan, K. K., Xiao, P. Wei., \& Su, C. H. (2015). The effects of learning styles and meaningful learning on the learning achievement of gamification health education curriculum. Eurasia Journal of Mathematics, Science and Technology Education, 11(5), 1211-1229. https://doi.org/10.12973/eurasia.2015.1413a

*Fotaris, P., Mastoras, T., Leinfellner, R., \& Rosunally, Y. (2016). Climbing up the leaderboard: An empirical study of applying gamification techniques to a computer programming class. Electronic Journal of E-Learning, 14(2), 95-110.

Fredricks, J. A., Blumenfeld, P. C., \& Paris, A. H. (2004). School engagement: Potential of the concept, state of the evidence. Review of Educational Research, 74(1), 59-109. https://doi.org/10.3102/00346543074001059

Fredricks, J. A., \& McColskey, W. (2012). The measurement of student engagement: A comparative analysis of various methods and student self-report instruments. In: Christenson S., Reschly A., Wylie C. (Eds.), Handbook of Research on Student Engagement. Springer, Boston, MA. https://doi.org/10.1007/978-1-4614-2018-7_37

*García, I., \& Cano, E. (2018). A computer game for teaching and learning algebra topics at undergraduate level. Computer Applications in Engineering Education, 26(2), 26-340. https://doi.org/10.1002/cae.21887

*Goehle, G., \& Wagaman, J.(2015). The Impact of Gamification in Web Based Homework. Taylor \& Francis Online, 6, 557-569. https://doi.org/10.1080/10511970.2015.1122690

*González, A. (2018). Turning a traditional teaching setting into a feedback-rich environment. International Journal of Educational Technology in Higher Education. https://doi.org/10.1186/s41239-018-0114-1

*Gressick, J., \& Langston, J. B. (2017). The Guilded Classroom: Using Gamification to Engage and Motivate Undergraduates. Journal of the Scholarship of Teaching and Learning, 17(3), 109-123. https://doi.org/10.14434/v17i3.22119 


\section{Macrothink}

*Hakulinen, Lasse, Tapio Auvinen, \& Ari Korhonen. (2013). Empirical Study on the Effect of Achievement Badges in TRAKLA2 Online Learning Environment. Proceedings - 2013 Learning and Teaching in Computing and Engineering, LaTiCE 2013, 47-54.

Hamari, J., Koivisto, J., \& Sarsa, H. (2014). Does gamification work? - A literature review of empirical studies on gamification. Proceedings of the Annual Hawaii International Conference on System Sciences. https://doi.org/10.1109/HICSS.2014.377

Hamari, J., \& Tuunanen, J. (2014). Player Types: A Meta-synthesis. Transactions of the Digital Games Research Association, 1(2), 29-53. https://doi.org/10.26503/todigra.v1i2.13

*Hannig, A., Lemos, M., Spreckelsen, C., Ohnesorge-Radtke, U., \& Rafai, N. (2013). Skills-OMat: Computer supported interactive motion-and game-based training in mixing alginate in dental education. Journal of Educational Computing Research, 48(3), 315-343. https://doi.org/10.2190/EC.48.3.c

*Hanus, M. D., \& Fox, J. (2015). Assessing the effects of gamification in the classroom: A longitudinal study on intrinsic motivation, social comparison, satisfaction, effort, and academic performance. Computers and Education, 80, 152-161. https://doi.org/10.1016/j.compedu.2014.08.019

*Haruna, H., Hu, X., Chu, S. K. W., Mellecker, R. R., Gabriel, G., \& Ndekao, P. S. (2018). Improving sexual health education programs for adolescent students through game-based learning and gamification. International Journal of Environmental Research and Public Health, 15(9). https://doi.org/10.3390/ijerph15092027

Hesson, M., \& Shad, K. F. (2007). A student-centered learning model. American Journal of Applied Sciences, 4(9), 628-636. https://doi.org/10.3844/ajassp.2007.628.636

*Hew, K. F., Huang, B., Chu, K. W. S., \& Chiu, D. K. W. (2016). Engaging Asian students through game mechanics: Findings from two experiment studies. Computers and Education, 92-93, 221-236. https://doi.org/10.1016/j.compedu.2015.10.010

*Hong, G. Y., \& Masood, M. (2014). Effects of Gamification on Lower Secondary School Students 'Motivation and Engagement. International Journal of Social, Education, Economics and Management Engineering, 8(12). https://doi.org/10.5281/zenodo.1096962

*Huang, B., Hew, K. F., \& Lo, C. K. (2018). Investigating the effects of gamification-enhanced flipped learning on undergraduate students behavioral and cognitive engagement. Interactive Learning Environments, 0(0), 1-21. https://doi.org/10.1080/10494820.2018.1495653

Huang, B., Hew, K. F., \& Lo, C. K. (2019a). Investigating the effects of gamification-enhanced flipped learning on undergraduate students' behavioral and cognitive engagement. Interactive Learning Environments, 27(8), 1106-1126. https://doi.org/10.1080/10494820.2018.1495653 
Huang, B., Hew, K. F., \& Lo, C. K. (2019b). Investigating the effects of gamification-enhanced flipped learning on undergraduate students' behavioral and cognitive engagement. Interactive Learning Environments, 27(8), 1106-1126. https://doi.org/10.1080/10494820.2018.1495653

*Huang, B., Hwang, G. J, Hew, K. F., \& Warning, P. (2019). Effects of gamification on students' online interactive patterns and peer-feedback. Distance Education, 40(3), 350-379. https://doi.org/10.1080/01587919.2019.1632168

Huang, R., Ritzhaupt, A. D., Sommer, M., Zhu, J., Stephen, A., Valle, N., Hampton, J., \& Li, J. (2020). The impact of gamification in educational settings on student learning outcomes: a meta-analysis. Educational Technology Research and Development, 68, 1875-1901. https://doi.org/10.1007/s11423-020-09807-z

Huesca Juárez, G., \& Medina Herrera, L. M. (2019). Learning gain study in a strategy of flipped learning in the undergraduate level. International Journal on Interactive Design and Manufacturing, 13(4), 1245-1258. https://doi.org/10.1007/s12008-019-00594-3

Hunicke, R., Leblanc, M., \& Zubek, R. (2004). MDA: A formal approach to game design and game research. AAAI Workshop - Technical Report, WS-04-04, 1-5.

Inhelder, B., \& Piaget, J. (2013). The growth of logical thinking from childhood to adolescence: An essay on the construction of formal operational structures. In The Growth of Logical Thinking from Childhood to Adolescence: An Essay on the Construction of Formal Operational Structures. https://doi.org/10.4324/9781315009674

Jaftha, N., Cristina, Flavia, Morone, P., \& Chircop, T. (2020). Knowing the Students ' Game-Playing Characteristics as a Prerequisite for Successful Gamification in Education. Journal of Education and Development, 4(3), 73-87. https://doi.org/10.20849/jed.v4i3.829

*Jesus, G. M. de, Ferrari, F. C., Paschoal, L. N., Souza, S. do R. S. de, Porto, D. de P., \& Durelli, V. H. S. (2020). Is It Worth Using Gamification on Software Testing Education? An Extended Experience Report in the Context of Undergraduate Students. Journal of Software Engineering Research and Development, 8, 1-19. https://doi.org/10.5753/jserd.2020.738

*Jiménez-Hernández, E. M., Oktaba, H., Díaz-Barriga, F., \& Piattini, M. (2020). Using web-based gamified software to learn Boolean algebra simplification in a blended learning setting. Computer Applications in Engineering Education, 28(6), 1591-1611. https://doi.org/10.1002/cae.22335

*Kaneko, K., Saito, Y., Nohara, Y., Kudo, E., \& Yamada, M. (2016). A Game-Based Learning Environment Using the ARCS Model at a University Library. Proceedings - 2015 IIAI 4th International Congress on Advanced Applied Informatics, IIAI-AAI 2015. https://doi.org/10.1109/IIAI-AAI.2015.285

*Kermek, D., Novak, M., \& Kaniski, M. (2018). Two years of gamification of the course - 
Lessons learned. 201841 st International Convention on Information and Communication Technology, Electronics and Microelectronics, MIPRO 2018 Proceedings. https://doi.org/10.23919/MIPRO.2018.8400140

*Khan, A., Ahmad, F. H., \& Malik, M. M. (2017). Use of digital game based learning and gamification in secondary school science: The effect on student engagement, learning and gender difference. Education and Information Technologies, 22, 2767-2804. https://doi.org/10.1007/s10639-017-9622-1

Koivisto, J., \& Hamari, J. (2019). The rise of motivational information systems: A review of gamification research. In International Journal of Information Management, 45, 191-210. https://doi.org/10.1016/j.ijinfomgt.2018.10.013

*Kolovou, A., Den Van Heuvel-Panhuizen, M., \& Koller, O. (2013). An Intervention Including an Online Game to Improve Grade 6 Students' Performance in Early Algebra. Journal for Research in Mathematics Education. 44(3), 510-549. https://doi.org/10.5951/jresematheduc.44.3.0510

*Lam, Y. W., Hew, K. F., \& Chiu, K. F. (2018). Improving argumentative writing: Effects of a blended learning approach and gamification. Language Learning and Technology, 22(1), 97-119.

Landers, R. N. (2014). Developing a Theory of Gamified Learning: Linking Serious Games and Gamification of Learning. Simulation and Gaming, 45(6), 752-768. https://doi.org/10.1177/1046878114563660

Landers, R. N., \& Armstrong, M. B. (2017). Enhancing instructional outcomes with gamification: An empirical test of the Technology-Enhanced Training Effectiveness Model. Computers in Human Behavior, 71, 499-507. https://doi.org/10.1016/j.chb.2015.07.031

*Laskowski, M. (2015). Implementing gamification techniques into university study path - A case study. IEEE Global Engineering Education Conference, EDUCON, 582-586. https://doi.org/10.1109/EDUCON.2015.7096028

*Leaning, M. (2015). A study of the use of games and gamification to enhance student engagement, experience and achievement on a theory-based course of an undergraduate media degree. Journal of Media Practice, 16(2), 155-170. https://doi.org/10.1080/14682753.2015.1041807

Liu, D., Santhanam, R., \& Webster, J. (2017a). Research Commentary Toward Meaningful Engagement : a Framework for Design and Research of Gmified. MIS Quarterly.

Liu, D., Santhanam, R., \& Webster, J. (2017b). Toward meaningful engagement: A framework for design and research of gamified information systems. MIS Quarterly: Management Information Systems, 41(4), 1011-1034. https://doi.org/10.25300/MISQ/2017/41.4.01

Manzano-León, A., Camacho-Lazarraga, P., Guerrero, M. A., Guerrero-Puerta, L., 
Aguilar-Parra, J. M., Trigueros, R., \& Alias, A. (2021). Between level up and game over: A systematic literature review of gamification in education. Sustainability (Switzerland), 13(4), 1-14. https://doi.org/10.3390/su13042247

*Mese, C., \& Dursun, O. O. (2019). Effectiveness of Gamification Elements in Blended Learning Environments. Turkish Online Journal of Distance Education, 20(3), 119-142. https://doi.org/10.17718/tojde.601914

*Morillas Barrio, C., Munoz-Organero, M., \& Sanchez Soriano, J. (2016). Can Gamification Improve the Benefits of Student Response Systems in Learning? An Experimental Study. IEEE Transactions on Emerging Topics in Computing, 4(3), 429-438. https://doi.org/10.1109/TETC.2015.2497459

Muñoz-Carpio, J. C., Cowling, M., \& Birt, J. (2019). Piloting experiential learning through $360^{\circ}$ Video and $3 \mathrm{D}$ printing to improve system modelling. ACM International Conference Proceeding Series, 23-28. https://doi.org/10.1145/3348400.3348411

*Morris, B. J., Dragovich, C., Todaro, R., Balci, S., \& Dalton, E. (2019). Comparing Badges and Learning Goals in Low- and High-Stakes Learning Contexts. Journal of Computing in Higher Education, 31(3), 573-603.

Nacke, L. E., \& Deterding, S. (2017). The maturing of gamification research. Computers in Human Behavior, 71, 450-454. https://doi.org/10.1016/j.chb.2016.11.062

*Naik, V., \& Kamat, V. (2016). Adaptive and Gamified Learning Environment (AGLE). Proceedings - IEEE 7th International Conference on Technology for Education, T4E 2015, 7-14. https://doi.org/10.1109/T4E.2015.23

Nguyen, T. T. H., Ishmatova, D., Tapanainen, T., Liukkonen, T. N., Katajapuu, N., Makila, T., \& Luimula, M. (2017). Impact of Serious Games on Health and Well-being of Elderly: A Systematic Review. Proceedings of the 50th Hawaii International Conference on System Sciences, (2017), 3695-3704. https://doi.org/10.24251/hicss.2017.447

*Ortiz-Rojas, M., Chiluiza, K., \& Valcke, M. (2019). Gamification through leaderboards: An empirical study in engineering education. Computer Applications in Engineering Education, 27(4), 777-788. https://doi.org/10.1002/cae.12116

*Pan, W. Fu. (2017). The Effects of Using the Kinect Motion-Sensing Interactive System to Enhance English Learning for Elementary Students. Educational Technology and Society, 20(2), 188-200.

*Pechenkina, E., Laurence, D., Oates, G., Eldridge, D., \& Hunter, D. (2017). Using a gamified mobile app to increase student engagement, retention and academic achievement. International Journal of Educational Technology in Higher Education. https://doi.org/10.1186/s41239-017-0069-7

Petri, G., \& von Wangenheim, C. G. (2016). How to evaluate educational games: A systematic literature review. Journal of Universal Computer Science, 22(7), 992-1021. https://doi.org/10.3217/jucs-022-07-0992 


\section{Macrothink}

*Poondej, C., \& Lerdpornkulrat, T. (2016). The Development of Gamified Learning Activities to Increase Student Engagement in Learning. Australian Educational Computing, 31(2).

*Pozo Sánchez, S., López Belmonte, J., Fuentes Cabrera, A., \& López Núñez, J. A. (2020). Gamification as a Methodological Complement to Flipped Learning-An Incident Factor in Learning Improvement. Multimodal Technologies and Interaction, 4(2), 2-13. http://dx.doi.org/10.3390/mti4020012

*Preist, C., \& Jones, R. (2015). The use of games as extrinsic motivation in education. Conference on Human Factors in Computing Systems - Proceedings, 3735-3738 https://doi.org/10.1145/2702123.2702282

Rapp, A., Hopfgartner, F., Hamari, J., Linehan, C., \& Cena, F. (2019). Strengthening gamification studies: Current trends and future opportunities of gamification research. In International Journal of Human Computer Studies, 127, 1-6 https://doi.org/10.1016/j.ijhcs.2018.11.007

Reeves, T. C., \& Lin, L. (2020). The research we have is not the research we need. Educational Technology Research and Development. https://doi.org/10.1007/s11423-020-09811-3

Reeves, T. C., \& Reeves, P. M. (2015). Educational Technology Research in a VUCA World. Educational Technology, 55(2), 26-30.

Retnowati, E., Ayres, P., \& Sweller, J. (2018). Collaborative learning effects when students have complete or incomplete knowledge. Applied Cognitive Psychology, 32(6), 681-692. https://doi.org/10.1002/acp.3444

Rodríguez, I., Puig, A., Tellols, D., \& Samsó, K. (2020). Evaluating the effect of gamification on the deployment of digital cultural probes for children. International Journal of Human Computer Studies, 137(October 2019), 102395. https://doi.org/10.1016/j.ijhcs.2020.102395

*Rojas-López, A., Rincón-Flores, E. G., Mena, J., García-Peñalvo, F. J., \& Ramírez-Montoya, M. S. (2019). Engagement in the course of programming in higher education through the use of gamification. Universal Access in the Information Society, 18, 583-597. https://doi.org/10.1007/s10209-019-00680-z

*Rueckert, D., Pico, K., Kim, D., \& Calero Sánchez, X. (2020). Gamifying the foreign language classroom for brain-friendly learning. Foreign Language Annals, 53(4), 686-703. https://doi.org/10.1111/flan.12490

Ryan, R. M., \& Deci, E. L. (2000). Intrinsic and Extrinsic Motivations: Classic Definitions and New Directions. Contemporary Educational Psychology, 25(1), 54-67. https://doi.org/10.1006/ceps.1999.1020 
*Sáez-López, J. M., Miller, J., Vascuez-Cano, E., \& Domínguez-Garrido, M. C. (2015). Exploring Application, Attitudes and Integration of Video Games: MinecraftEdu in Middle School. Educational Technology \& Society 18(3), 114-128gamification as

*Sancho-Vinuesa, T., Masià, R., Fuertes-Alpiste, M., \& Molas-Castells, N. (2018). Exploring the effectiveness of continuous activity with automatic feedback in online calculus. Computer Applications in Engineering Education, $26(1), \quad 62-74$. https://doi.org/10.1002/cae.21861

Seaborn, K., \& Fels, D. I. (2015). Gamification in theory and action: A survey. International Journal of Human Computer Studies, 74(February), 14-31. https://doi.org/10.1016/j.ijhcs.2014.09.006

*Segura-Robles, A., Fuentes-Cabrera, A., Parra-González, M. E., \& López-Belmonte, J. (2020). Effects on Personal Factors Through Flipped Learning and Gamification as Combined Methodologies in Secondary Education. Frontiers in Psychology, 11(June), 1-8. https://doi.org/10.3389/fpsyg.2020.01103

Slavin, R., \& Smith, D. (2009). The relationship between sample sizes and effect sizes in systematic reviews in education. In Educational Evaluation and Policy Analysis, 31(4). https://doi.org/10.3102/0162373709352369

*Smiderle, R., Rigo, S.J., Marques, L. B., de Miranda, Coelho, J. A. P., \& Jacques, P. A. (2020). The impact of gamification on students' learning, engagement and behavior based on their personality traits. Smart Learning Environments, 7(3). https://doi.org/10.1186/s40561-019-0098-x

*Stansbury, J. A., \& Earnest, D. R. (2017). Meaningful Gamification in an Industrial/Organizational Psychology Course. Teaching of Psychology, 44(1), 38-45. https://doi.org/10.1177/0098628316677645

*Stapinski, Lexine A., Bill Reda, Nicola C. Newton, Siobhan Lawler, Daniel Rodriguez, Catherine Chapman, \& Maree Teesson. (2018). Development and Evaluation of 'Pure Rush': An Online Serious Game for Drug Education. Drug and Alcohol Review, 37(S1), 420-428. https://doi.org/10.1111/dar.12611

*Sun-Lin, H. Z., \& Chiou, G. F. (2017). Effects of self-explanation and Game-reward on sixth graders' algebra variable learning. Educational Technology and Society, 20(4), 126-137.

*Sun-Lin, H. Z., \& Chiou, G. F. (2019). Effects of gamified comparison on sixth graders' algebra word problem solving and learning attitude. Educational Technology and Society, $22(1), 120-130$.

Sun, J. C. Y., \& Hsieh, P. H. (2018). Application of a gamified interactive response system to enhance the intrinsic and extrinsic motivation, student engagement, and attention of English learners. Educational Technology and Society, 21(3), 104-116. https://www.jstor.org/stable/26458511 
Swacha, J. (2021). State of research on gamification in education: A bibliometric survey. Education Sciences, 11(2), 1-15. https://doi.org/10.3390/educsci11020069

Sweller, J. (1988). Cognitive load during problem solving: Effects on learning. Cognitive Science, 12(2), 257-285. https://doi.org/10.1016/0364-0213(88)90023-7

Sweller, J., van Merriënboer, J. J. G., \& Paas, F. (2019). Cognitive Architecture and Instructional Design: 20 Years Later. Educational Psychology Review, 31(2), 261-292. https://doi.org/10.1007/s10648-019-09465-5

Torres-Toukoumidis, A., Carrera, P., Balcazar, I., \& Balcazar, G. (2021). Descriptive Study of Motivation in Gamification Experiences from Higher Education: Systematic Review of Scientific Literature. Universal Journal of Educational Research, 9(4), 727-733. https://doi.org/10.13189/ujer.2021.090403

*Tsay, C. H. H., Kofinas, A. K., Trivedi, S. K., \& Yang, Y. (2020). Overcoming the novelty effect in online gamified learning systems: An empirical evaluation of student engagement and performance. Journal of Computer Assisted Learning, 36(2), 128-146. https://doi.org/10.1111/jcal.12385

*Tsay, C. H. H., Kofinas, A., \& Luo, J. (2018). Enhancing student learning experience with technology-mediated gamification: An empirical study. Computers and Education, 121, 1-17. https://doi.org/10.1016/j.compedu.2018.01.009

Van Roy, R., Deterding, S., \& Zaman, B. (2018). Uses and gratifications of initiating use of gamifed learning platforms. Conference on Human Factors in Computing Systems Proceedings, 565, 1-5. https://doi.org/10.1145/3170427.3188458

*Wang, Y. H. (2017). The effectiveness of using cloud-based cross-device irs to support classical chinese learning. Educational Technology and Society, 20(2), 127-141.

Webster, J., \& Watson, R. (2002). Analyzing the Past to Prepare for the Future: Writing a Literature Review. MIS Quarterly, 26(2), xiii-xxiii.

Werbach, K., \& Hunter, D. (2012). The Gamification Toolkit: Game Elements. For the Win: How Game Thinking Can Revolutionize Your Business.

*Wichadee, S., \& Pattanapichet, F. (2018). Enhancement of Performance and Motivation through Application of Digital Games. Teaching English with Technology, 18(1), 77-92.

Wood, L. C., \& Reiners, T. (2015). Gamification. In Encyclopedia of Information Science and Technology (3rd 3039-3047. ed.). IGI Global. https://doi.org/10.4018/978-1-4666-5888-2.ch297

Wu, Y. L. (2018). Gamification design: A comparison of four m-learning courses. Innovations in Education and Teaching International, 55(4), 470-478. https://doi.org/10.1080/14703297.2016.1250662

*Yildirim, Ibrahim. (2017). The Effects of Gamification-Based Teaching Practices on Student Achievement and Students' Attitudes toward Lessons. Internet and Higher Education, 
33, 86-92. https://doi.org/10.1016/j.iheduc.2017.02.002

*Zainuddin, Z. (2018). Students' learning performance and perceived motivation in gamified flipped-class instruction. Computers and Education, 126, 75-88. https://doi.org/10.1016/j.compedu.2018.07.003

Zainuddin, Z., Chu, S. K. W., Shujahat, M., \& Perera, C. J. (2020). The impact of gamification on learning and instruction: A systematic review of empirical evidence. Educational Research Review, 30, 100326. https://doi.org/10.1016/j.edurev.2020.100326

Zainuddin, Z., Shujahat, M., Haruna, H., \& Chu, S. K. W. (2020). The role of gamified e-quizzes on student learning and engagement: An interactive gamification solution for a formative assessment system. Computers and Education, 145, 103729. https://doi.org/10.1016/j.compedu.2019.103729

\section{Notes}

Note 1. 'Gamified interaction' is used in this study as an umbrella term when discussing gamified pedagogy without making distinctions between the types of games.

Note 2. Only in this section, frequencies refer to the number of articles included in the Systematic Review (72), in the following sections of the article, frequencies refer to the number of studies (75) included in the Systematic Review.

\section{Copyright Disclaimer}

Copyright for this article is retained by the author(s), with first publication rights granted to the journal.

This is an open-access article distributed under the terms and conditions of the Creative Commons Attribution license (http://creativecommons.org/licenses/by/3.0/). 